\title{
GAIA Level 2 Maternal Death
}

National Cancer Institute

\section{Source}

National Cancer Institute. GAIA Level 2 Maternal Death. NCI Thesaurus. Code C127998.

GAIA Level 2 Maternal Death is defined by three criteria: first, diagnosis of a pregnancy, in the absence of level 1 criteria, as established by either of the following requirements: a) last menstrual period date; b) Serial symphysio fundal height examinations; second, death of the mother while pregnant or within 42 days of termination of pregnancy, irrespective of the duration and the site of the pregnancy; third, documentation of the maternal cause of death wherein one of the following requirements must be met: a) Direct: abortive outcome, hypertensive disorder, obstetric hemorrhage, pregnancy related infection, other obstetric complications, unanticipated complications; b) Indirect: non obstetric complications; c) Death during pregnancy, childbirth, and the puerperium: other or coincidental; d) Unspecified: unknown or undetermined. 